Jurnal Kesmas Asclepius

Volume 2, Nomor 2, Desember 2020

e-ISSN: 2684-8287

p-ISSN: 2656-8926

DOI: https://doi.org/10.31539/jka.v2i2.1396

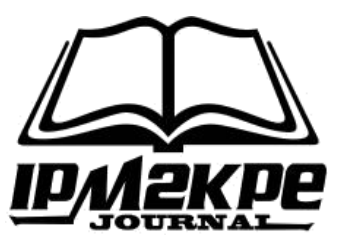

\title{
PENATALAKSANAAN PENGOBATAN TUBERCULOSIS PARU
}

\author{
Juli Andri ${ }^{1}$, Henni Febriawati ${ }^{2}$, Yusuf Randi ${ }^{3}$, Harsismanto $\mathrm{J}^{4}$, \\ Asih Dewi Setyawati ${ }^{5}$ \\ Universitas Muhammadiyah Bengkulu ${ }^{1,2,3,4,5}$ \\ aancapella88@gmail.com ${ }^{1}$
}

\begin{abstract}
ABSTRAK
Tujuan penelitian ini adalah untuk melihat bagaimana penatalaksanaan pengobatan tuberculosis paru. Penelitian ini menggunakan pendekatan kualitatif. Hasil penelitian menunjukkan 1 dari 3 orang pasien tuberculosis tidak patuh dalam berobat tuberculosis di wilayah kerja Puskesmas Sukamerindu Kota Bengkulu. Faktor yang mendukung ketidakpatuhan berobat yaitu kurangnya pengetahuan panduan berobat tuberculosis. Simpulan, pasien yang tidak patuh disebabkan karena sudah merasa sudah sembuh dan malas untuk mengambil obat lagi di Puskesmas Sukamerindu, PMO sudah mengerti dengan tugasnya sebagai seorang PMO.
\end{abstract}

Kata Kunci : Kepatuhan Minum Obat, Pemberi Obat, PMO, Tuberculosis Paru

\section{ABSTRACT}

The purpose of this study was to see how the management of pulmonary tuberculosis treatment. This research uses a qualitative approach. The results showed that 1 in 3 tuberculosis patients did not comply with tuberculosis treatment in the working area of the Sukamerindu Public Health Center, Bengkulu City. Factors that support treatment non-compliance are the lack of knowledge of tuberculosis treatment guidelines. In conclusion, patients who do not comply are caused because they feel he is already healed and are lazy to take more medicine at the Sukamerindu Health Center, PMO already understands his duties as a PMO.

Keywords: Compliance with Medication, Drug Giver, PMO, Pulmonary Tuberculosis

\section{PENDAHULUAN}

Salah saut penyakit menular yang masih menjadi permasalahan kesehatan di dunia sampai saat ini adalah tuberkulosis dan merupakan penyakit infeksi menular yang upaya pengendaliannya menjadi salah satu target dunia yaitu Suistainable Development Goals (SDGs). SDGs menetapkan Tuberkulosis (TB) sebagai tujuan di bidang kesehatan yaitu mengakhiri epidemic AIDS, tuberkulosis (Bappenas, 2017).

Data World Health Organization (WHO) tahun 2014 menunjukkan jumlah penderita TB Paru pada tahun 2013 di benua Asia terdapat 56\%, Afrika 29\%, Regional Mediterania Timur 8\%, Eropa 4\% dan yang paling kecil beban penderita TB adalah wilayah Amerika 3\% dari total jumlah penderita TB paru di dunia (WHO, 2014). Tuberculosis paru diperkirakan masih menyerang 9,6 juta orang dan menyebabkan 1,2 
juta kematian pada tahun 2014. Data WHO di kawasan`Asia Tenggara menunjukkan bahwa kematian akibat TB Paru sekitar 2.000 jiwa setiap hari (WHO, 2015).

Tuberculosis (TB) merupakan penyakit menular yang disebabkan oleh infeksi mycobacterium tuberculosis. Penyakit ini dapat menyebar bersama malaria dan HIV/AIDS, tuberculosis menjadi salah satu penyakit yang pengendaliannya menjadi komitmen global dalam MDGs (Dinkes Bengkulu, 2014).

TB Paru adalah penyakit yang dapat diobati dan disembuhkan dengan pengobatan selama 6 bulan sampai 1 tahun (Info DATIN Kementerian Kesehatan RI, 2016). Apabila penderita menghentikan pengobatan maka kuman TB Paru akan mulai berkembang biak lagi. Hal ini berarti penderita mengulangi pengobatan intensif selama 2 bulan pertama (WHO, 2013). Pengobatan yang tidak teratur dan kombinasi obat yang tidak lengkap, dapat menimbulkan kekebalan ganda kuman TB terhadap Obat Anti Tuberkulosis (OAT) atau Multi Drug Resistance (MDR). WHO (2013) memperkirakan di Indonesia terdapat 6.800 kasus baru TB dengan Multi Drug Resistance (TB MDR) setiap tahun.

Bengkulu pada tahun 2011 penderita TB Paru BTA (+) berjumlah 618 orang, jumlah penderita yang diobati berjumlah 618 orang, jumlah penderita sembuh 272 orang (82,67\%). Dengan angka kesuksesan (91,34\%). Pada tahun 2012 penderita Tuberculosis Paru (+) berjumlah 611 orang jumlah penderita yang diobati berjumlah 611 orang. Jumlah penderita yang sembuh 283 orang $(97,92 \%)$ dengan angka kesuksesan (98,96\%). Pada tahun 2013 penderita Tuberculosis Paru (+) berjumlah 566 orang, jumlah penderita yang diobati berjumlah 566 orang. Jumlah penderita yang sembuh berjumlah 265 orang $(82,55 \%)$ dengan angka kesuksesan $(95,64 \%)$. Untuk penderita tuberculosis paru di Kota Bengkulu di Daerah Kecematan Sukamerindu, Puskesmas Sukamerindu mempunyai 47 orang tuberculosis paru BTA (+), angka ini menempati urutan pertama di Bengkulu (Dinkes Provinsi Bengkulu, 2014).

Menurut Tabrani (2010) strategi DOTS (Directly Observed Treatment Short Course) merupakan prioritas utama dari World Health Organization (WHO) dalam mengontrol angka kejadian TB Paru. Untuk mendukung strategi DOTS, dibutuhkan kedisiplinan dari penderita TB itu sendiri dalam pengobatannya. Selain itu untuk meningkatkan kepatuhan minum obat pasien TB Paru dibutuhkan pengawasan langsung oleh Pengawas Menelan Obat (PMO) (Netty, 2013). Dari hasil penelitian Pameswari et al., (2016) tingkat kepatuhan minum obat pada penderita tuberkulosis paru belum mencapai $100 \%$.

\section{METODE PENELITIAN}

\section{Jenis dan Rancangan Penelitian}

Penelitian ini menggunakan pendekatan kualitatif. Penelitian ini bersifat deskriptif yaitu untuk mengetahui gambaran penatalaksanaan pengobatan tuberculosis paru di wilayah kerja Puskesmas Sukamerindu Kota Bengkulu. Metode penelitian deskriptif adalah suatu metode penelitian yang dilakukan dengan tujuan utama untuk membuat gambaran atau deskripsi tentang suatu keadaan secara objektif.

\section{Waktu dan Lokasi Penelitian}

Penelitian ini dilakukan di Puskesmas Sukamerindu Kota Bengkulu, sedangkan yang menjadi objek penelitian adalah pasien tuberculosis paru yang berobat di Puskesmas Sukamerindu Kota Bengkulu. 


\section{Sumber Informasi}

Pasien yang menderita tuberculosis paru dan masih aktif berobat di Puskesmas Sukamerindu Kota Bengkulu sebanyak 3 orang. Pengawas Minum Obat (PMO) penderita tuberculosis paru sebanyak 3 orang. Perawat/pemberi obat di Puskesmas Sukamerindu Kota Bengkulu sebanyak 1 orang

\section{Teknik Keabsahan Data}

Untuk menguji keabsahan data digunakan teknik triangulasi yaitu sebuah teknik menilai keabsahan data dengan cara mengecek data yang telah diperoleh. Pada penelitian ini dengan menggunakan triangulasi sumber. Pada penelitian ini sumber informasi untuk memperoleh data didapat dari pasien yang menderita tuberculosis, pengawas minum obat atau peran keluarga, petugas yang bertugas di poli penyakit dalam. Rekaman arsip wawancara dan dokumentasi, serta file-file dan dokumen yang berkaitan dengan penelitian, serta dengan diskusi penelitian dengan pembimbing akademik.

\section{HASIL PENELITIAN}

Tabel. 1

Karekteristik Informan Responden Menurut Usia

\begin{tabular}{ccc}
\hline Informan & Usia & PMO \\
\hline Informan 1 & 44 tahun & Istri \\
Informan 2 & 61 tahun & Cucu \\
Informan 3 & 38 tahun & Adik Kandung \\
\hline
\end{tabular}

Dari tabel 1 diketahui bahwa informan dikategorikan ke dalam 3 kategori yaitu dengan komposisi usia termuda berumur 38 tahun, usia tertua 61 tahun, yang terdiri dari 1 laki-laki dan 2 perempuan. PMO pertama istrinya sebagai PMO informan $1 \mathrm{Tn}$. MU, informan kedua cucunya sebagai PMO informan $2 \mathrm{Ny}$. DA, informan ketiga adik kandungnya sebagai PMO informan $3 \mathrm{Ny}$. SU.

\section{Kepatuhan Minum Obat pada Pasien dan Pengawas Menelan Obat (PMO) Kepatuhan Minum Obat}

Adapun hasil wawancara diperoleh dari informan bahwa seluruh 3 kategori informan TB paru di wilayah kerja Puskesmas Sukamerindu terdapat 1 orang yang tidak patuh terhadap minum obat disebabkan karena merasa sudah sembuh. Dimana pengobatan tuberculosis paru berlangsung selama 6 bulan. Pengobatan awal selama 2 bulan (fase intensif) pasien harus mengonsumsi Obat Anti Tuberculosis (OAT) setiap hari dalam seminggu sampai 2 bulan. Adapun obat yang dikonsumsi antara lain rifampisin, isoniasid, pirasinamid, etambutol dan jumlah hari/kali menelan obat sebanyak 120 butir selama 2 bulan. Pengobatan tahap lanjutan berlangsung selama 4 bulan, pasien harus mengonsumsi obat anti tuberculosis 3 kali seminggu, adapun obat yang dikonsumsi antara lain rifampisin, isoniasid, pirasinamid dan jumlah hari/kali menelan obat sebanyak 216 butir selama 4 bulan.

\section{Pengawas Minum Obat}

Adapun hasil wawancara pada informan pengawas minum obat di wilayah kerja Puskesmas Sukamerindu diperoleh 3 pengawas minum obat sudah mengerti dengan 
tugas sebagai seorang PMO, dimana tugas seorang PMO adalah untuk mengingatkan pasien tuberculosis untuk teratur minum obat, mengingatkan jadwal pengambilan obat, ataupun sampai pada jadwal pemeriksaan dahak.

Adapun hasil wawancara pada informan kepatuhan minum obat sebagai berikut :

Informan 1 pasien Tn. MU mengatakan bahwa :

"sudah, karno anjuran dokter tu udah dikasih petunjuk sama dokter, iya. iya dek.Kan mau ini mau sembuh, mau bener-bener sembuh. Oh..ya dek.iya minum,minum setiap hari, iya dek kalu gak hari senin hari selasa bisa diambil.Iya dek, karna kebanyakan obat itu tadi,udah terlalu lama kan ngonsumsi obat terus.Iyo, kalo dianjurkan dokter setiap hari senin pagi, iya dek, itu udah bapak tetapkan harinya senin, selasa, rabu.Iya dek, kalu misalnyo anjuran dokter,ibaratnyo belum terasa enak masih diambil obatnya".

Informan 2 pasien Ny. DA mengatakan bahwa :

"Sudah, yang selama 2 bulan itu sehari $3 x$ rutin minum obat, iya saya nurut aja aturan dokter, yang 4 bulan itu seminggu $3 x$ minum obatnya. Iya saya minum setiap hari, biar cepat sembuh .iya rutin saya minum setiap hari. Iya kalau disuruh hari apa ngambil obat, saya pegi ke puskesmas.Idak nak, soalnyo mbah sudah setiap hari minum obat. Iya setiap hari senin saya ke puskesmas memeriksa dahak kalu pagipagi saya pergi ke puskesmas sukamerindu.Iya, saya minum 3 hari satu minggu. Iya, saya dengan anak saya mengambilnya dipuskesmas sukamerindu...”.

Informan 3 pasien Ny. SU mengatakan bahwa :

"Yo kapan dikasih tu kan jadwalnyo tu kan ado yang 1 kali, ado yang 2 kali, ado yang 3 kali. Idak samo obatnyo tu ado yang 1 kali sehari, ado yang 2 hari sekalikan jadi ibu nurut itulah peraturan itu ajo. Iyolah idak berani ibu lebih-lebih dosis, ibu pernah makan obat nak makan idak nak makan, laju 18 hari dirumah sakit itu mangkonyo ibu ati-ati nian kalo nak minum obat ko ibu tanyo dulu makan dulu apo idak, ibu pernah tu ibu nak makan tapi mulut ko idak nerimo cak tu na jadi ibu lajukan ajo obat akhirnyo apo 18 hari dirumah sakit.Kalo lah sehat idak ibu minum lagi eh kalo masih iko ko masih ibu minum, Ibu habiskan kalo la sehat nak ngapo pulo.masih yo terus.Ibu tengok kesehatan ibu kalo idak sakit lagi ndak ngapo ibu ndak ngambik, kalo ibu la sehat idak ibu ndak ngambik lagi eh kalo masih iko yo masih jangankan orang nyuruh ibu dewek yang pai situ. Idak pulo memang lah tebiaso dari kecik, kecik dulu keno malaria. Yo kapan dak pemerikasaan dahak kemaren?pemeriksaan pernah juga dak di apo namonyo tu di Bhayangkara dah tu disiko pernah jugo, pokoknyo kapan disuruh ibu perikso. Yang 4 bulan tu, iyo kalo yang 4 bulan tu minum terus. kalo ibu masih meraso perlu ibu ngambik.

\section{Pengawas Minum Obat}

Adapun hasil wawancara dengan pengawas minum obat sebagai berikut :

Informan pengawas menelan obat (PMO) informan $1 \mathrm{Tn}$. MU mengatakan bahwa:

"Iya memberikan dorongan penderita agar minum obat. Selama 6 bulan. Ibu tetap minumkan obatnyo mungkin itu kalu yang keluar berwarna merah, efek sampingannyo mungkin udah dio keluar itu dio cepat sembuh kalu minum itu. Iyo, pertamo ibu kasih dorongan motivasi supaya bapak cepat sembuh, yang keduo ibu dampingi kalu misalnyo bapak nak minum obat, ahh..yang ketigo ibu itu, ibu bantu ambikkan obat kek minumnyo. Setuju dek,Setuju nian ibu, karno adonyo PMO ado 
motivasi penderita biar cepek sembuh. Iyo, yang pertamo meningkatkan penderita supayonyo cepek sembuh bapaknyo kan. Aa.. yang keduo, ibu menginginkan yo bapak tu kalo misalnyo ibu dorong, supayo minum obat teratur.Iyo dek. Supayo cepek sembuh. Bapak tu biar cepek minum obatnyo biar teratur. Kalu lamonyo, ibu tu la lamo 3 bulan. Iyo ibu awasi selalu biarnyo ingek untuk minum obek. Iyo, ibu,ibu omongi bapak ndak cepek sembuh dak?kalau bapak nak cepek sembuh ibu cepek kasihnyo untuknyo minum obek teratur. Iyo, biar bapak cepek sembuh dek. Suami ibu itu dek...”.

Informan pengawas menelan obat (PMO) informan $2 \mathrm{Ny}$. DA mengatakan bahwa :

"Iyo,iyo kan iko kan nak ngasih kito dorongan cakmano ngasih obatnyo, cakmano kito jagonyo. Kalu idak salah la 4 bulan yo. Iyo, kalo cak itu tu biasonyo obat tu diteruskan iyo jangan sampai telat minumnyo, tepat waktunyo kalu pagi minum obat pagi kalu siang obat siang kan ado aturannyo dari dokterkan. Iyo, jangan sampai kito tanyo kan cakmano, kek iko kan apo cakmano kito tengok. cak itu, yo cak itu lah. Kito, kalau abang kek mbah kemaren cak iko ajo ngasihkan cakmano dak nyuruhnyo cakmano nyo minum supayo cepek sembuh jadi nyo tu kalo nyo susah kito tolong ngambik ubeknyo kan, cak itulah... elok kalu cak itu, masalahnyo pastikan teratur kito minumkan obatnyo kan, mbah tu adolah kemajuannyo elok kan. Jadi namonyo orang tuo galak lupo namonyo, cakmano yo kito tu lah yang ingekkan.

Teratur, kalau selamo ko teraturkan, kalau abang kerjo berangkat pagi, yo kasih dulu letakkan dekek mbah disuruh minumkan, kalau siang telpon kek ayukkan, kalau malam abang ado yo namonyo awak ngurusi awak sebagai pengawas minuman ko minum obat ko kan. Iko mbah, nenek jatuhnyo kalau abang cucunyo..."

Informan pengawas menelan obat (PMO) informan 3 Ny. SU mengatakan bahwa :

"Iyo lah tau, yang pertamo memberikan untuk ayuk supayo dio minum ubek teratur, yang keduo ngasih motivasi dio supayo dio cepek sembuh, agar penyakitnyo tu idak terlalu lamolah dio rasokan. Tindakan yang abang lakukan tu memberikan obat tetap abang teruskan karno bagi abang tu kalo air seninyo berwarno merah tu idak berbahaya karena kecek dokter kemaren tu kalo air seninyo pas kencing berwarno merah itu tu efek samping dari pado obat yang diminumnyo tu dek. Motivasi abang tu untuk kesembuhan ayuk tu supayo cepek yaitu mengingatkan ayuk supayo dio minum ubek terus, mengingatkan ayuk tu supayo dio tu cepek sembuhAbang jadi PMO untuk ayuk abang ko kurang lebih sekitar 3 bulan. Untuk mengawasinyo tu kalo abang lagi idak kerjo yo abang awasi teruskan selamo dio minim ubek tapikan abang kerjo jadi idak bisa untuk selalu mengawasi, jadi kalo abang pai kerjo pagi baliknyo sore tu yo abang kasih ayuk tu pagi-pagi, lalu untuk siangnyo tu dan sorenyo tu abang siapkan ubeknyo tu jadi biar ayuk minum dewek kelak. Hubungan abang kek ayuk tu kakak kandung abang dek."

\section{Pemberi Obat (Perawat)}

Adapun hasil wawancara dengan perawat (Pemberi Obat) sebagai berikut Informan perawat mengatakan bahwa :

"Iyolah dek pasti ado idak mungkin idak ado, cakmano pasien nak minum obat kalau dak ado obatnyo kan. Kalo pasiennyo baru kito jelaskan kalu pasien lamo nyo lah ngerti dewek dek lah bisokan. Iyo dari awal pasien tu datang kek kito dak dek la didiagnosa kenai TB Paru jadi kito jelaskan caro pengobatannyo cakmano cak itu. 
Iyo kito omongi secara pelan-pelan pasien TB tu dek mudah tersinggung kito omongin pak penyakit bapak ni menular jadi kalau mau datang kepuskesmas gunakan masker kita harus menjaga lingkungan kita. Iyo kito tanyo terus dek apo ado keluhan apo ado cakmano bapak tu biasonyo pasien tu datang ngambil obat sekalian nyampaikan keluhan. Kalo untuk 2015 ini dari januari sampai sekarang patuh segalo dek karno baru kan belum ado yang muak minum obat tu.Hari senin kek selasa cuman 2 hari ajo..."

\section{PEMBAHASAN}

\section{Kepatuhan Minum Obat Pada Pasien TB Paru}

Hasil penelitian diperoleh informasi bahwa (1) informan yang tidak patuh disebabkan karena sudah merasa sudah sembuh. Hasil penelitian yang sudah dilakukan Dewi et al., (2019) di wilayah kerja Puskesmas I dan III Denpasar Utara dari 42 responden didapatkan jumlah penderita TB Paru yang memiliki kepatuhan tinggi yaitu sebanyak 29 orang $(69 \%)$, 9 orang $(21,4 \%)$ memiliki tingkat kepatuhan sedang dan 4 orang $(9,5 \%)$ memiliki kepatuhan rendah. Data tersebut menunjukkan bahwa sebagian besar responden memiliki tingkat kepatuhan tinggi. Tingkat kepatuhan tinggi salah satunya dapat dipengaruhi oleh adanya motivasi. Motivasi dalam meningkatkan kesadaran dan keinginan berobat penderita sangat berpengaruh terhadap keberhasilan pengobatan TBC. Terkadang walaupun gejala penyakit mulai memberat, tetapi apabila penderitanya tidak merasa begitu sakit, penderita cenderung untuk tidak mencari pengobatan.

Hasil penelitian di atas sejalan dengan hasil penelitian yang dilakukan oleh Putu et al., (2015) berdasarkan jawaban responden yang telah diteliti didapatkan tingkat kepatuhan minum obat yang tinggi yaitu sebesar $86.67 \%$. Tingginya tingkat kepatuhan pengobatan pada responden dapat disebabkan oleh beberapa faktor pendukung, seperti obat-obatan dan layanan diberikan secara gratis, pusat pelayanan kesehatan yang mudah diakses oleh masyarakat serta adanya keinginan dari dalam diri untuk sembuh. Hasil penelitian di atas juga didukung hasil penelitian yang dilakukan oleh Sari et al., (2014) dikatakan bahwa 92 pasien yang menjadi responden dalam penelitian masih patuh dalam menjalani terapi antituberkulosis terbukti dengan tetap menjalani terapi antituberkulosis sampai selesai (selama 6 bulan) dan tidak terdapat obat sisa setiap bulan. Hal ini disebabkan karena adanya faktor yang tidak perlu rangsangan dari luar, yang berasal dari diri sendiri berupa motivasi, keyakinan, sikap dan kepribadian dari masing-masing responden. Sedangkan faktor yang perlu rangsangan dari luar berupa dukungan sosial dalam bentuk dukungan emosional dari anggota keluarga yang lain ataupun teman.

Berdasarkan hasil penelitian diperoleh informasi bahwa secara garis besar dapat disimpulkan dari 3 informan terdapat 1 yang tidak patuh dalam penatalaksanaan pengobatan, yaitu terdiri dari 2 orang informan patuh terhadap pengobatan tuberculosis paru dan 1 orang informan tidak patuh dalam pengobatan tuberculosis paru. Ketidakpatuhan informan disebabkan informan sudah merasa sembuh dari penyakitnya, itu dapat disimpulkan bahwa kurangnya pengetahuan dari informan untuk kepatuhan berobat.

Hasil penelitian menunjukan bahwa PMO sudah mengerti tugasnya sebagai seorang PMO. Hasil wawancara perawat/pemberi obat didapatkan bahwa ketersedian Obat Anti Tuberculosis (OAT) selalu ada pada waktu pasien atau penderita tuberculosis paru mengambilnya. 
Penelitian yang dilakukan Pongoh et al., (2015) menunjukkan bahwa bahwa tenaga kesehatan di Puskesmas Kota Manado sebagian besar berumur 25-36 tahun $(52,0 \%)$, jenis kelamin terbanyak perempuan 65 responden $(86,7 \%)$. Tenaga kesehatan di Puskesmas Kota Manado semuanya (100\%) memiliki pengetahuan, sikap, tindakan yang baik terhadap pengobatan TB.

Menurut Kemenkes RI (2014) untuk menjamin keteraturan pengobatan maka diperlukan adanya Pengawasan Menelan Obat (PMO). PMO adalah seseorang yang ditunjuk dan dipercaya untuk mengawasi dan memantau penderita TB dalam meminum obatnya secara teratur dan tuntas. Hasil wawancara di atas sejalan dengan hasil penelitian yang dilakukan oleh Putu et al., (2015) berdasarkan kepemilikan Pengawas Minum Obat (PMO), dari hasil penelitian ini didapatkan bahwa 94,4\% responden memiliki pengawas minum obat. Tujuh belas orang responden yang memiliki PMO menyatakan bahwa PMO selalu mengingatkan untuk minum obat, selalu mengingatkan untuk mengambil obat dan mengecek dahak tepat waktu, serta menegur responden apabila lupa minum obat.

Penelitian yang dilakukan Gego \& Djuma (2019) menunjukkan responden yang memiliki pengetahuan baik tentang TB sebanyak 28/34 responden, semua responden memiliki sikap dan perilaku baik tentang kepatuhan minum obat, semua pendamping minum obat berperan baik dalam keberhasilan pengobatan. Keberhasilan pengobatan TB di Puskesmas Borong di pengaruhi oleh pengetahuan, kepatuhan, sikap, perilaku pasien yang baik dan ditunjang oleh peran dari PMO yang sangat baik.

\section{SIMPULAN}

Berdasarkan hasil penelitian wawancara pada 3 informan didapatkan gambaran penatalaksanaan pengobatan tuberculosis paru di wilayah Kerja Puskesmas Sukamerindu Kota Bengkulu ditemukan pasien yang tidak patuh disebabkan karena sudah merasa sudah sembuh dan malas untuk mengambil obat lagi di Puskesmas Sukamerindu, PMO sudah mengerti dengan tugasnya sebagai seorang PMO.

Ketersedian obat anti tuberculosis selalu ada pada saat pasien atau penderita tuberculosis paru. Ketidakpatuhan minum obat pasien tuberculosis paru, terdiri dari 2 informan patuh terhadap pengobatan tuberculosis paru, 1 informan tidak patuh terhadap pengobatan tuberculosis paru.

\section{SARAN}

Hasil penelitian dapat memberikan suatu masukan bagi Puskesmas Sukamerindu dan evaluasi dalam pelaksanaan pengobatan tuberculosis paru yang telah dilaksanakan sehingga dapat meningkatkan pelayanan kesehatan terhadap pasien terutama pasien tuberculosis paru di wilayah kerja Puskesmas Sukamerindu dengan cara senantiasa memberikan informasi bagi masyarakat terutama penderita tuberculosis paru mengenai penyakit tuberculosis tentang penatalaksanaan pengobatan minum obat tuberculosis paru. 


\section{DAFTAR PUSTAKA}

Bappenas. (2017). Tujuan Pembangunan Berkelanjutan. Kementerian PPN/Bappenas, $12-14$

Dinkes Provinsi Bengkulu. (2014). Profil Kesehatan Kota Bengkulu 2009

Gego, G., \& Djuma, A. W. (2019). Gambaran Keberhasilan Pengobatan pada Pasien Tuberkulosis Paru BTA (+) Positip di Wilayah Puskesmas Borong Kabupaten Manggarai Timur. Politeknik Kesehatan Kementerian Kesehatan Kupang

Info Datin Kementerian Kesehatan RI. (2016). Tuberkulosis : Temukan Obati Sampai Sembuh

Netty, E. (2013). Hubungan Peran Keluarga dengan Kepatuhan Minum Obat Pada Pasien Tuberkulosis di Puskesmas Kecamatan Jagakarsa. Health Quality, 4(2),8390.www.poltekkesjakarta1.ac.id

Pameswari, P., Halim, A., \& Yustika, L. (2016). Tingkat Kepatuhan Penggunaan Obat pada Pasien Tuberkulosis di Rumah Sakit Mayjen H. A Thalib Kabupaten Kerinci. JSFK (Jurnal Sains Farmasi \& Klinis), 2(2), 116-121. DOI: 10.29208/jsfk.2016.2.2.60

Pongoh, N. E., Palendang, H. M. F., \& Rombot, D. V. (2015). Gambaran Perilaku Tenaga Kesehatan terhadap Pengobatan Tuberkulosis Paru di Puskesmas Kota Manado. Jurnal Kedokteran Komunitas dan Tropik, III(2), 108-117. https://ejournal.unsrat.ac.id/index.php/JKKT/article/view/7779

Putu, N., Reza, A., Trasia, R. F., Indriyani, K. D., \& Aryani, P. (2015). Gambaran Kepatuhan Minum Obat pada Penderita Tuberkulosis Paru di Wilayah Kerja Puskesmas Bebandem, Karangasem. E-Jurnal Medika Udayana, 3(10). https://ojs.unud.ac.id/index.php/eum/article/download/11928/8234

Sari, I. D., Yuniar, Y., \& Syaripudin, M. (2014). Studi Monitoring Efek Samping Obat Antituberkulosis Fdc Kategori 1 di Provinsi Banten dan Provinsi Jawa Barat. Media Penelitian dan Pengembangan Kesehatan, 24(1), 28-35. DOI: 10.22435/mpk.v24i1.3484.28-35

Tabrani, R. (2010). Ilmu Penyakit Paru. Jakarta: Trans Info Media

WHO. (2013). Global Tuberculosis Control: WHO Report 2013. Geneva 2013

WHO. (2014). Global TB Report Edition Global. https://www.who.int/teams/globaltuberculosis-programme/tb-reports

World Health Organization. (2015). Global Tuberculosis Report 